\title{
O Paranismo atualizado: a democracia cristã e o planejamento no primeiro governo Ney Braga ${ }^{1}$
}

Neda Mohtadi Doustdar ${ }^{2}$

- Enviado em 30/01/2016

- Aprovado em 30/04/2016

\section{RESUMO}

Este artigo é um resumo da tese que trata do primeiro governo Ney Braga (1961 a 1965), reconhecido como uma experiência inovadora, que, ancorado no programa do Partido Democrata Cristão e no ideário da Democracia Cristã, editou o Plano Paranaense de Desenvolvimento, elaborado pela Sagmacs, sob a direção do Pe. Lebret. A tese procura mostrar que as ações desse governo estavam mais próximas da ideologia desenvolvimentista, adotando postulados típicos da abordagem centro-periferia de corte cepalino, do que das diretrizes que pudessem emanar da Democracia Cristã. Constata, assim, uma continuidade dos modelos desenvolvimentistas dos governos estaduais e da União que o antecederam, tratando-se, portanto, de um tipo recorrente nos governos. Nesse processo, aponta que os intelectuais que fizeram referência a essa experiência estavam reeditando uma visão muito particular do Paraná conhecida como "Paranismo", ou seja, um sistema de valores assentados na ideia do Paraná como um Brasil diferente. A partir daí o estudo pode afirmar que esse paranismo é uma modalidade de ideologia, voltada para a integração de um território dividido pelo processo de ocupação. As contribuições teóricas de Mannheim foram fundamentais para o desenvolvimento deste estudo, em especial no que se refere à ideologia e ao papel de uma camada de intelectuais, a intelligentzia, no planejamento. Igual relevância teve o estudo de Miriam Limoeiro sobre o desenvolvimentismo e a ideologia desenvolvimentista, presentes nos discursos de Juscelino Kubitschek e Jânio Quadros. Muito importante foram as investigações de Maria Helena Oliva Augusto, sobre a Codepar, e de Francisco Borja de Magalhães, sobre o modelo paranaense de planejamento, obras precursoras na análise e interpretação do planejamento no Estado do Paraná.

Palavras-chave: Governo Ney Braga. Democracia Cristã. Partido Democrata Cristão. Sagmacs. Ideologia desenvolvimentista.

\section{INTRODUÇÃO}

1 Tese de doutorado defendida em 03/12/2010, sob orientação da Prof ${ }^{a}$ Dr $^{a}$ Maria Tarcisa Silva Bega no Programa de Pósgraduação em Sociologia da UFPR. Versão completa disponível na Biblioteca Digital da UFPR http://dspace.c3sl.ufpr.br:8080/dspace/ handle/1884/29936

2 Graduada em Ciências Sociais pela UFPR. Mestre em História pela UFPR. Doutora em Sociologia pela UFPR. Pesquisadora do IPARDES. E-mail: neda@ipardes.pr.gov.br 
Este artigo é um resumo da minha tese de doutorado. A tese trata do primeiro governo Ney Braga (1961 a 1965), que foi reconhecido como uma experiência inovadora e analisado como uma experiência política extremamente positiva para o Paraná, quando ele teria se destacado da média dos governantes brasileiros pela sua visão moderna da função do dirigente político. Segundo os estudiosos do seu período governamental, ele teria montado no Paraná um sistema estadual de planejamento público responsável pela modernização da economia e sociedade paranaenses. Mais do que isso, esse sistema seria original no Brasil e concebido quase exclusivamente por técnicos locais e, por isso mesmo, veio a se constituir em um modelo de desenvolvimento. Além disso, sua ação modernizadora e inovadora estaria ancorada no programa do Partido Democrata Cristão ${ }^{3}$ e seria o resultado da influência do ideário e dos princípios da Democracia Cristã que orientavam as ações do seu governo e que acabaram por editar o Plano de Desenvolvimento do Paraná, ${ }^{4}$ elaborado pela Sagmacs - Sociedade de Análises Gráficas e Mecanográficas Aplicadas aos Complexos Sociais, uma empresa de pesquisa e planejamento fundada e dirigida no Brasil pelo Padre Lebret, o que teria reforçado ainda mais a originalidade do planejamento adotado.

Dessa forma, o Pe. Lebret apareceu como tendo extrema relevância para a experiência paranaense, chegando mesmo a ser visto como um modelo da atividade de planejamento. Assim, Pe. Lebret, com os princípios de Economia e Humanismo, a Democracia Cristã e o projeto paranaense de desenvolvimento econômico formaram quase uma unidade orgânica que contrapôs não só um governo, mas todo o Paraná com o restante do país como um marco diferenciador.

A hipótese que orientou minha tese contraria frontalmente essas ideias. Procurei demonstrar que não havia uma experiência original de planejamento que tivesse uma unidade estrutural, tanto nos seus objetivos como nos meios organizativos para atingir esses objetivos, que permitisse falar de um projeto ou de um modelo paranaense de desenvolvimento. Procurei demonstrar ainda que a ideia de um projeto ou um modelo de desenvolvimento era o resultado do esforço de uma intelectualidade acompanhado de um saber técnico consistente, para justificar ou legitimar uma experiência, de resto digna de elogios.

Essa demonstração passou por três momentos. Primeiro, que não havia uma correspondência entre os princípios da Democracia Cristã e do Partido Democrata Cristão (PDC), assumidos

\footnotetext{
3 Programas do Partido Democrata Cristão (PDC) - 1945 e 1961.

4 PARANÁ. Plano de Desenvolvimento do Paraná. Sagmacs, 1963. v. 1-2. (mimeografado).
} 
particularmente por Ney Braga no plano discursivo (nas Mensagens enviadas à Assembléia Legislativa) e as práticas governamentais, expressas nas políticas públicas.

Segundo, que essa foi uma construção a posteriori feita por intelectuais desejosos de racionalizar suas experiências pessoais de maneira muito específica. Nesse sentido, procurei mostrar que as ações do governo Ney Braga estavam mais próximas da ideologia desenvolvimentista, adotando postulados típicos da abordagem centro-periferia de corte cepalino, do que das diretrizes que pudessem emanar da Democracia Cristã. Dessa forma, constatei que havia uma continuidade dos modelos desenvolvimentistas dos governos estaduais e da União que o antecederam, mostrando que existia um tipo recorrente nos governos. Nesse processo, apontei que os intelectuais que fizeram referência a essa experiência estavam reeditando uma visão muito particular do Paraná conhecida como "Paranismo", ou seja, um sistema de valores assentados na ideia do Paraná como um Brasil diferente.

Finalmente, registrei que se recorreu ao transplante de uma doutrina desenvolvida nas condições da Europa para condições bem diferentes do Brasil. Mais ainda, evidenciei que isso só foi possível porque essa doutrina vinha incorporando uma problemática típica dos países do Terceiro Mundo, que era o desenvolvimento comandado pelo Estado. Dessa forma, comprovei na tese que se tratou de um artefato ideológico para dar uma determinada conotação ao que não passou do esforço de uma elite que via sua hegemonia política sendo contestada por novos grupos emergentes na sociedade paranaense. A partir daí afirmei que essa modalidade de ideologia, conhecida como "paranismo", estava voltada para a integração de um território dividido pelo processo de ocupação.

Foi central na tese as contribuições de Karl Mannheim para a sustentação teórica da prática de planejamento numa sociedade democrática. Ao desenvolver uma sociologia do conhecimento ele agrupou no mesmo plano teórico uma sociologia do planejamento com o conceito de intelligentzia, e que foi fundamental para a análise do papel dos intelectuais. Segundo Mannheim, os intelectuais sendo capazes de encarar o mesmo problema sob diferentes aspectos, estão aptos a realizar a "síntese das perspectivas parciais", atuando de forma racional nas esferas da vida social.

No múltiplo uso da ideologia, apropriei-me do seu significado forte que, segundo Stoppino, surge da reformulação da conexão entre ideologia e poder, a partir do conceito de falsa consciência, e diz respeito a todo um sistema de crenças e de juízos de valor que cobrem ou mascaram os motivos reais de comando ou de obediência que confere à ideologia o seu caráter de falsa motivação. 
Também foi central na tese o pensamento de Miriam Limoeiro, uma vez que ela coloca a ideologia do desenvolvimentismo no campo mais amplo da ideologia do desenvolvimento, e que acompanha o processo de expansão do sistema capitalista nas regiões subdesenvolvidas em fase de crescimento, porém no momento em que o desenvolvimento espontâneo não é mais possível. No centro do campo das ideias associadas ao desenvolvimento está a necessidade de dinamizar a economia para ampliar sua participação e os benefícios do país no sistema capitalista. Com isso, o desenvolvimentismo centrado no desenvolvimento, é uma nova dimensão da ideologia dominante, sendo a representação de uma classe ou fração dominante que apresenta o desenvolvimento como sendo o objetivo e interesse de toda sociedade e assumido como um dado de interesse geral. Assim, a sua força mobilizadora, isto é, a sua aderência à realidade, está na ideia de que a prosperidade atingirá a todos.

Numa definição próxima, para Bielschowsky, o desenvolvimentismo é uma ideologia de superação do subdesenvolvimento mediante a industrialização capitalista apoiada e planejada pelo Estado. Portanto, o planejamento econômico e a intervenção do Estado na economia são aspectos centrais do desenvolvimentismo, visto como essencial para a promoção do desenvolvimento econômico e social.

Das proposições de Miriam Limoeiro e de Bielschowski derivei que o Projeto Paranaense de Desenvolvimento, desde que inscrito na "ordem geral" do desenvolvimentismo, contemplou a intervenção organizada e sistemática do Estado na economia, por meio de um plano, e a veiculação, para toda a comunidade, de um sistema de ideias em que a intervenção é uma resposta dos dirigentes políticos às esperanças e expectativas dessa comunidade.

Para dar conta da análise proposta, esta tese foi demonstrada em quatro capítulos. No capítulo 1 expus a relação entre a Doutrina Social da Igreja (DSI), a Democracia Cristã (DC), a emergência dos partidos democratas cristãos na Europa e a fundação, no Brasil, do Partido Democrata Cristão (PDC), em 1945.

O desenvolvimento do capítulo começou com a discussão da DSI e sua relação com a DC, onde explorei principalmente as encíclicas relacionadas ao tema social e à presença do ser humano no mundo, quando o magistério católico dedicou-se à chamada "questão social" e abordou a condição dos operários em todos os seus aspectos. Na orientação da DSI, em traços gerais, a autoridade é vista como instrumento para tornar possível o bem comum em uma comunidade pluralista, 
dirigindo e coordenando a ação de todos e atuando com uma força moral baseada na liberdade e no sentido de responsabilidade de cada um.

Nos escritos de Jacques Maritain, reunidos sob o título o Homem e o Estado e editados após o término da Segunda Guerra Mundial, o povo é a própria substância do corpo político e possui o direito natural de se autogovernar, colocando-se acima do Estado. Para essa análise foram importantes as contribuições de alguns pensadores católicos, como Tomás de Aquino, o próprio Maritain e um sistematizador contemporâneo da DSI, Ildefonso Camacho.

Na sequência, discuti o surgimento do movimento democrata cristão na Europa e sua transformação gradativa de movimento em um partido organizado, quando mostrei que, ao termino da Segunda Guerra Mundial, ressurgiram os partidos democratas cristãos que haviam desaparecido da Europa com a emergência do nazismo e do fascismo. Este foi então o quadro que destaquei como sendo um fenômeno tipicamente europeu.

O sucesso desses partidos repercutiu no Brasil, que passava pelo processo de redemocratização e de construção de novos partidos políticos. Nesse contexto particular ocorreu o Primeiro Congresso da Democracia Cristã em Montevidéu, em abril de 1947, promovido pelos poucos militantes da Democracia Cristã na América Latina. Nessa ocasião, os participantes do Congresso ficaram convencidos de que a conquista da democracia, como meio de impedir a ascensão de movimentos totalitários, não seria factível sem a justiça social e que só seriam alcançadas com o desenvolvimento econômico dos países latino-americanos.

A criação do Partido Democrata Cristão no Brasil foi feita por políticos que não encontraram espaço nos grandes partidos que então se organizavam, e a incorporação dos militantes da Democracia Cristã, principalmente os jovens militantes católicos da Vanguarda Democrática, entre os quais estava presente Franco Montoro, deu ao PDC uma característica particular, a de ser o partido dos pedecistas e dos democratas cristãos, uma cisão que perdurou durante toda a vida do partido. Para esta discussão, apoiei-me em larga medida nos escritos de Franco Montoro, por onde enfoquei a experiência do Partido Democrata Cristão com o detalhamento dos programas de 1946 e de 1961 até o seu desaparecimento, em virtude da decretação do Ato Institucional n. ${ }^{\circ}$ 2, em 1965.

Dessa forma, assinalei que desde os seus primeiros ensaios de organização na América Latina e no Brasil, a Democracia Cristã constatava a existência de um fator crítico e restritivo, que era o subdesenvolvimento, e que deveria ser superado. Assim, procurei demonstrar que a 
Democracia Cristã foi forçada a incorporar em seu ideário uma variável não europeia associada às condições de profunda injustiça social e de atraso das sociedades nacionais da América Latina, o desenvolvimento capitaneado pelo Estado e as reformas sociais para superar as injustiças. Dessa forma, o PDC aproximava-se do ideário de outros partidos que colocavam como meta o desenvolvimento.

Ao mesmo tempo, mostrei que a hierarquia da Igreja no Brasil estava mais preocupada em recuperar os privilégios que havia perdido com a proclamação da República e a separação da Igreja do Estado. Sua atuação no Centro Dom Vital e na Liga Eleitoral Católica, ambas dirigidas por Alceu Amoroso Lima, deu a ela um meio de atuar em todos os partidos políticos sem a necessidade de um partido católico ou mesmo de um partido democrata cristão, por mais conservador que ele pudesse ser.

Apontei que na convenção nacional do PDC realizada em abril de 1961, foi estabelecido um programa de atuação política imediata, fundamentado na defesa do nacionalismo (estranho para uma corrente doutrinária que se propunha a ser supranacional em virtude da concepção que tinha do Estado, extraída dos ensinamentos de Maritain), de uma política externa independente e da redistribuição da propriedade rural para eliminar o latifúndio improdutivo. Com isso, sinalizei que o PDC ingressava na corrente do desenvolvimentismo.

Em síntese, demonstrei neste capítulo, como os partidos democratas cristãos europeus surgiram até a constituição problemáica do PDC no Brasil, uma vez que sua organização pouco tinha a ver com um movimento democrata cristão prévio. Isso permitiu definir um problema que formou a base para o capítulo seguinte, a ausência, no Brasil, das condições que, na Europa, propiciaram o surgimento da DC e dos partidos democratas cristãos, não havendo, portanto, uma correspondência entre as ações do governo Ney Braga, membro do PDC, e os princípios da Democracia Cristã.

No capítulo 2 destaquei a inserção do governo Ney Braga no ideário da Democracia Cristã e no programa do PDC. Tratei da figura pública de Ney Braga, em especial na sua aproximação da Democracia Cristã e do Partido Democrata Cristão. Em seguida, expus as ações do governo Ney Braga que traduziam o projeto de desenvolvimento, confrontando-as com a Doutrina Social da Igreja (DSI), os postulados da Democracia Cristã e o programa do PDC que são invocados para justificar o governo. 
Nesse capítulo fiz uma análise do sistema de planejamento implantado no Paraná, comparandoo com as práticas de planejamento que havia no contexto nacional e com outras experiências brasileiras, particularmente com Minas Gerais, no governo de JK e com governos anteriores do Paraná, os de Bento Munhoz e de Moyses Lupion, para assinalar a existência de um tipo recorrente em todos eles. Para isso, foram essenciais as Mensagens de governo e as investigações de Maria Helena Oliva Augusto, sobre a Companhia de Desenvolvimento Econômico do Paraná (Codepar), e de Francisco Magalhães, sobre a montagem e o desmanche do sistema de planejamento paranaense, obras precursoras na análise e interpretação do planejamento no Estado do Paraná.

O nome de Ney Braga foi apontado para a direção nacional do PDC em oposição a Franco Montoro, que representava a tradição do PDC. Ney Braga não estava vinculado aos dirigentes católicos paulistas que controlavam o partido, surgindo como representante de uma tendência nacional capaz de realizar a renovação do PDC contra as velhas lideranças paulistas.

Dessa forma, demonstrei que a vinculação de Ney Braga com a Democracia Cristã não se deu por motivo ideológico ou doutrinário, mas em virtude de injunções eleitorais, uma vez que ele não tinha uma legenda pela qual candidatar-se a deputado federal e, anteriormente, quando fora prefeito de Curitiba, não recebeu o apoio do PDC. Ademais, ressaltei que as coligações partidárias nacionais não encontravam correspondência nos estados, que sempre se organizavam em função dos interesses locais. Daí concluí a dificuldade de assinalar qualquer fidelidade a princípios políticos e doutrinários.

Por isso, não há como estabelecer uma relação de fidelidade programática com a gestão de Ney Braga. Assim, pude demonstrar que, além de a Democracia Cristã ser uma experiência europeia que não se traduz no Brasil, a fragmentação política não assegurava meios de atuação política se nem mesmo existia unidade programática para isso, portanto, tornava-se difícil assinalar a fidelidade de um político à doutrina de seu partido nessas condições de desagregação política e partidária existente no Brasil.

A candidatura Ney Braga ao governo do Estado ocorreu no âmbito de uma coalizão oposicionista nacional encabeçada por Jânio Quadros, do Partido Democrata Cristão, em aliança com a União Democrática Nacional. O lançamento do nome de Jânio Quadros como candidato à Presidência da República, foi feito no Rio de Janeiro, por meio do Movimento Popular Jânio Quadros (MPJQ), uma entidade não partidária, o que era um indicativo da fragmentação partidária levada ao extremo. Nesse ambiente, deu-se a campanha de Ney Braga, vinculada estreitamente à 
campanha de Jânio Quadros. Além disso, mostrei também que o apoio dado pela Igreja, por meio do clero e da hierarquia católica, e que Ney Braga recebeu da Liga Eleitoral Católica (LEC) inspirava-se no anticomunismo, que predominava na orientação da Igreja.

O PDC, ao propor uma reforma para atender às peculiaridades regionais, assumia cada vez mais um programa desenvolvimentista e nacionalista, que contrariava os princípios da Democracia Cristã, que sempre se opunha ao fortalecimento dos Estados Nacionais em defesa de uma associação internacional democrata cristã, como também não expressava qualquer ideia que fosse minimamente próxima daquela que orientava a Democracia Cristã na Europa. Se era difícil associar o Partido Democrata Cristão do Brasil à mesma matriz doutrinária e ideológica que informava esses partidos na Europa, mais difícil ainda seria associar as ações do governo Ney Braga ao programa democrata cristão.

Nesse sentido, procurei demonstrar que o seu sistema de planejamento nada tinha de inovador, mesmo porque ele repetia práticas consagradas do planejamento estatal no Brasil. O verdadeiro objeto de seu plano de governo era dotar o Paraná de uma infraestrutura de transportes e de energia elétrica, o que estava perfeitamente em conformidade com a Comissão Mista Brasil - Estados Unidos, que, no início da década de 1950, definiu a implantação da infraestrutura de transportes e de energia elétrica como objetivo estratégico para assegurar o desenvolvimento da economia brasileira. Com isso, assinalei que essa política era inteiramente compatível com aquela que Juscelino Kubitschek ${ }^{5}$ adotara para o seu governo em Minas Gerais, dez anos antes, sob a denominação Binômio Energia e Transporte.

Além disso, mostrei que o governo de Bento Munhoz $^{6}$ deu a mesma ênfase aos aspectos relacionados com o desenvolvimento, organizando um sistema voltado para estimular projetos de investimentos que tivessem um sentido estratégico para a economia paranaense, concentrando-se na implantação de uma malha rodoviária que assegurasse a integração econômica do estado e na implantação da infraestrutura energética estadual, mediante a criação da Companhia Paranaense de Energia Elétrica (Copel) que passou a se ocupar do planejamento e da produção de energia elétrica no

5 OLIVEIRA, Juscelino Kubitschek. Realidades, perspectivas. Publicações da Secretaria da Educação de Minas Gerais, Coleção Cultural, n.5, Discursos 1951-1955. Impresso na Imprensa Oficial de Minas Gerais, Belo Horizonte, em Janeiro de 1955.

6 PARANÁ. Mensagem apresentada à Assembleia Legislativa do Estado por ocasião da abertura da Sessão Ordinária da $2^{\text {a }}$ Legislatura pelo senhor Bento Munhoz da Rocha Neto, governador do Paraná, Curitiba, 1951-1952. 
Paraná. Além disso, Bento Munhoz também se preocupou com a integração do estado no momento em que ainda se dava o processo de ocupação do Paraná.

Em seguida, indiquei também que Lupion $^{7}$ deu continuidade tanto à programação do plano energético do Paraná, como também dotou o estado de uma rede rodoviária capaz de integrar suas regiões. Com base nessas observações, demonstrei que as políticas de Ney Braga deram uma continuidade ao que estava sendo feito no estado e não se mantinham alheias ao desenvolvimentismo, mesmo que reduzido à industrialização.

Com isso, evidenciei que o projeto paranaense de desenvolvimento derivou da "ordem geral" do desenvolvimentismo, traduzida pela intervenção organizada e sistemática do Estado na economia, por meio de um plano e da veiculação, para toda a comunidade, de um sistema de ideias em que a intervenção fora uma resposta dos dirigentes políticos às esperanças e expectativas dessa comunidade.

Para isso foi de extrema importância em minha análise o papel dos intelectuais que racionalizaram um evento e dele participaram ativamente. $\mathrm{O}$ modelo paranaense de desenvolvimento no governo Ney Braga propôs medidas desenvolvimentistas que nasciam da afirmação dos interesses do Paraná no contexto nacional, isto é, a necessidade de adotar uma política de substituição de importações que afirmasse a ideia de um governo paranaense para os paranaenses.

Para isso mostrei que em todas as Mensagens ${ }^{8}$ encaminhadas à Assembleia Legislativa, Ney Braga define o Paraná como uma economia periférica em confronto com um centro dinâmico industrializado. A situação periférica da economia paranaense era explicada pelo fato de a maior parte da renda regional ser gerada pela cafeicultura, que era o seu setor dinâmico, mas que a maioria do capital empregado no setor era originário de outras regiões do país, particularmente de São Paulo, e sua remuneração era uma retirada sobre a economia regional. Nestes termos, o projeto desenvolvimentista do Paraná estava fundado numa ideia orientadora que reproduzia a problemática centro-periferia, do modelo cepalino, e, assim, fazia uma atualização para o Paraná da ideologia desenvolvimentista dominante em termos nacionais.

\footnotetext{
${ }^{7}$ PARANÁ. Mensagem apresentada à Assembleia Legislativa do Estado por ocasião da Abertura da Sessão Legislativa ordinária pelo senhor Moyses Lupion, governador do Paraná, Curitiba, 1956-1958-1960.

8 PARANÁ. Mensagem apresentada a Assembleia Legislativa pelo governador do Estado: Ney Aminthas de Barros Braga, 1961-1962-1963-1964-1965.
} 
A Companhia de Desenvolvimento Econômico do Paraná (Codepar) tinha por objetivo implantar formas mais dinâmicas e flexíveis de ação governamental mediante a racionalização do setor público, ao hierarquizar prioridades para investimentos mediante estudos e seleções de projetos necessários e com efeitos para a economia do Estado. A necessidade de fomento industrial levou à criação de um fundo específico de desenvolvimento econômico (FDE) cuja formação se dava mediante a captação compulsória de parte da renda da população para a formação de uma poupança forçada que seria gerida pela Codepar. Constatei que os recursos do FDE foram destinados prioritariamente para o setor de energia elétrica e para a construção de estradas.

Com isso sinalizei que além da dimensão estritamente econômica da ideologia desenvolvimentista havia também uma outra dimensão mobilizadora da ideologia e que se referia ao fato de a Codepar ter contribuido para a mudança de mentalidade social, ensinando a comunidade a mobilizar suas poupanças de modo a assegurar a expansão mais rápida dos serviços públicos básicos do Estado.

Para demonstrar que o projeto de desenvolvimento do Paraná foi uma elaboração a posteriori de uma intelectualidade, registrei a permanência dos quadros técnicos estatais responsáveis pela implantação do novo aparato de planejamento, cuja organização vinha de governos anteriores, como é o caso da Comissão de Planejamento do Desenvolvimento Econômico do Paraná (Pladep), que fora organizado no governo Lupion com o pessoal convocado pelo governo de Bento Munhoz para organizar as festividades do centenário da emancipação do Paraná e que elaborou o "Diagnóstico Sócio Econômico do Estado do Paraná", lançando as bases do planejamento para o desenvolvimento.

Parte desse mesmo quadro técnico também fora enviado para treinamento na Comissão Econômica para a América Latina (Cepal) e já compunha em grande medida o sistema estadual de planejamento. Nas gestões sucessivas de Bento Munhoz da Rocha, Moysés Lupion e Ney Braga foram adotadas medidas estratégicas pelo estado com o objetivo de assegurar o desenvolvimento nacional, definido pela industrialização, e que foi capaz de criar um mínimo de consenso entre as elites políticas. Com isso, registrei a permanência da estrutura estatal e da burocracia, independentemente da coloração governamental, bem como a relativa permanência de uma camada de intelectuais na estrutura do estado que perpassaram esses governos e que mantiveram entre si um contencioso muito forte. 
Junto a isso houve um fato relevante que foi a ocupação do Norte e do Extremo-Oeste e Sudoeste paranaense e que introduziu uma variável determinante na forma de fazer política e administrar o estado. Do ponto de vista político, houve a contestação da hegemonia política de um grupo de parentesco ligado a uma economia em decadência, à qual pertencia Ney Braga e Bento Munhoz. Além disso, havia uma variável administrativa que era a necessidade de tratar de conflitos pela posse da terra de enormes proporções e que atravessou todos os governos de 1950 a 1965 . Nesse contexto, o discurso político de Ney Braga visando legitimar-se pela Democracia Cristã é um deslocamento de nítido caráter ideológico, ou seja, da definição forte de ideologia proposta por Stoppino.

Diante disso, provei que não havia correspondência na relação das ações do Governo Ney Braga com os princípios da Democracia Cristã. Ademais, se existia uma relação com a política do PDC, ela tinha que ser buscada na problemática do desenvolvimento e não na sua versão ampla de desenvolvimento integral, que estava na base do pensamento do Padre Lebret, mas naquilo que o desenvolvimento tinha de mais reducionista, a mera industrialização. Esse foi o tema que analisei quando tratei da presença de Lebret no Paraná, no capítulo 3.

A análise da presença do Pe. Lebret no Paraná permitiu reforçar o primeiro tema, ou seja, a não correspondência entre os princípios da Democracia Cristã e as ações do governo, bem como o segundo tema, que se refere ao papel da intelectualidade racionalizando uma experiência, assim como serviu também de introdução para o terceiro tema que explorei para demonstrar a tese, ou seja, a construção de uma ideologia particular a partir do transplante para as condições do Brasil de uma experiência tipicamente europeia.

No capítulo 3 avaliei a presença de Lebret no Brasil e no Paraná, focando as causas e os prováveis motivos para a rejeição de suas ideias na prática e não no discurso, e procurei mostrar que o mesmo fenômeno que levou à sua rejeição no Brasil estava também presente no Paraná, pois ele decorreu da atuação dos setores católicos conservadores e do ambiente conturbado da política nacional que perpassava todos os estados brasileiros no período que antecedeu o golpe de Estado de 1964.

O capítulo teve início com a apresentação da vida e do pensamento de Pe. Lebret, dando especial destaque a sua atuação no sentido de organizar um movimento inspirado nos ensinamento sociais da Igreja e na organização de uma instituição que expressava os princípios desse movimento, e 
que veio a ser chamado movimento Economia e Humanismo. Expus a filiação dessas ideias à DSI, que vem a ser a matriz comum da Democracia Cristã e do movimento Economia e Humanismo.

Associado a esse assunto, analisei a natureza e a forma de atuação da empresa de pesquisa e planejamento fundada no Brasil por Lebret, a Sagmacs, que, de certa forma, consistia em operar os princípios da DSI nas condições dos países do Terceiro Mundo as quais colocavam para os católicos os problemas do atraso e das profundas injustiças sociais.

Apresentei e comentei dois trabalhos realizados pela Sagmacs: um relacionado à Região Sul e outro destinado especificamente ao Paraná, o Plano de Desenvolvimento do Paraná, ambos com base no Manual de Pesquisa Social, ${ }^{9}$ um método de investigação e de planejamento, elaborado pelo próprio Lebret. O tema central desse capítulo foi a demonstração de que essa sociedade procurava traduzir nos seus trabalhos de pesquisa e nas suas diretrizes os princípios de Economia e Humanismo.

Os dois itens finais do capítulo foram dedicados a duas modalidades de conflito que Lebret enfrentou no Brasil. O primeiro com a hierarquia e os intelectuais católicos, profundamente conservadores e imbuídos de um forte "anticomunismo", e o segundo, com o ambiente político vigente no país no período pré-1964, marcado por conturbações traduzidas pelo termo "golpismo". ${ }^{10}$

Para o desenvolvimento do capítulo recorri aos dois trabalhos feitos pela Sagmacs, às mensagens de Ney Braga à Assembleia Legislativa, ao Dicionário Histórico e Bibliográfico Brasileiro $^{11}$ e a entrevistas e depoimentos publicados na literatura sobre o tema. O pensamento de Lebret também foi visitado em algumas de suas próprias obras.

A presença de Lebret no Paraná e sua influência foi analisada com base nos trabalhos desenvolvidos pela Sagmacs no estado, começando pelo estudo da Comissão Interestadual da Bacia do Paraná-Uruguai, ${ }^{12}$ particularmente sobre os estados do Rio Grande do Sul, Santa Catarina e Paraná, e, em seguida, pela avaliação do Plano de Desenvolvimento do Paraná. O Governo do

9 LEBRET, Louis-Joseph. Manual de encuesta social. Madrid: Ediciones Rialp, 1961. v.1-2.

${ }^{10} \mathrm{O}$ conceito de golpismo está presente na tese de Maria Victória de Mesquita Benevides sobre a União Democrática Nacional (UDN). A autora estabelece a diferença entre golpe e golpismo, afirmando "as diferenças entre o golpe ocasional como um instrumento rápido e eficiente para a chegada ao poder e o golpismo como princípio político" (BENEVIDES, 1981, p.83-91).

${ }^{11}$ DHBB - DICIONÁRIO HISTÓRICO-BIOGRÁFICO BRASILEIRO: 1930-1983. Rio de Janeiro: ForenseUniversitária/Fundação Getúlio Vargas - Centro de Pesquisas e Documentação de História Contemporânea do Brasil/ FINEP, 2001.

12 SAGMACS - COMISSÃO INTERESTADUAL DA BACIA PARANÁ-URUGUAI (CIBPU). Problemas de desenvolvimento: necessidades e possibilidades dos Estados do Rio Grande do Sul, Santa Catarina e Paraná. São Paulo: Atlas, 1958, v.1-3. 
Paraná, por meio da Codepar, contratou em 1963, a equipe da Sagmacs que, junto com a Pladep, estruturou os elementos para a elaboração do Plano de Desenvolvimento para o Estado do Paraná, cujos resultados foram entregues ao governo em julho daquele ano.

Nesse contexto particular, em que o planejamento adquiria um caráter estratégico na promoção do desenvolvimento por parte do estado, a Sagmacs propunha uma forma de planejamento compatível com a ideia de desenvolvimento integral, concebido no âmbito do movimento Economia e Humanismo, para traduzir os princípios da DSI. Para Lebret e a Sagmacs, não se tratava de agregar medidas sociais paliativas a uma economia que por si mesma engendra o mal humano. Sua proposta consistia em instaurar um regime integralmente social e integralmente personalista, que garantisse a ascensão humana universal. O conceito de desenvolvimento de Lebret possuía uma dimensão comunitária, traduzida na necessidade da participação do povo que, ao compreender o que estaria sendo realizado, se associaria ao "projeto de desenvolvimento" e seria capaz de encontrar as fórmulas adequadas para sua participação, muito distantes das fórmulas clássicas. Dessa forma, registrei que essas ideias contrastavam com a concepção de desenvolvimento que imperava nos planos governamentais brasileiros, inclusive no Paraná, que se restringia, na prática, às medidas voltadas para assegurar a industrialização, particularmente, a industrialização acelerada.

Apresentei por meio das medidas governamentais analisadas que a ação do governo restringiu-se a algumas reformas administrativas que poderiam ser atribuídas ao plano e que as orientações deixadas pelo Pe. Lebret não deixaram marcas. A ausência de diretrizes e de propostas de intervenção impediu que se fizesse uma associação entre os princípios de "Economia e Humanismo" de um desenvolvimento harmonioso voltado para o ser humano como causa do objetivo do planejamento. Com isso, evidenciei que a invocação de Lebret, tanto pelo governo como pelos intelectuais, tinha um nítido caráter ideológico e, ao mesmo tempo, se prestava a certo nobilitamento dos intelectuais locais que tiveram a oportunidade de com ele trabalhar. Nesse sentido, mostrei que a presença de Lebret no Paraná nessa oportunidade, como pela ocasião do estudo patrocinado pela Comissão Interestadual da Bacia do Paraná - Uruguai, poderia ser traduzido, provavelmente, na reforma administrativa realizada em 1963.

Além disso, mencionei que a presença do Pe. Lebret foi também objeto de rejeição por parte da Igreja e de seus representantes intelectuais que, supostamente, seriam os porta-vozes da Democracia Cristã. Começei por alguns registros que serviram de indicativo do assunto para trazer uma situação conflitiva. 
Sua presença no Brasil foi descrita pelo intelectual católico Gustavo Corção, como o emissário de uma visão responsável pela influência do comunismo na Igreja Católica, devida particularmente à política de João XXIII. Ao lado disso, mostrei que as três principais e mais expressivas entidades criadas pela hierarquia católica no Brasil - Centro Dom Vital, Liga Eleitoral Católica e Ação Católica - preocupavam-se exclusivamente com o que veio a ser chamado a "construção da alma brasileira".

O Centro Dom Vital, editor da revista A Ordem, publicação associada ao movimento de "restauração católica", procurava garantir à Igreja maior presença na sociedade divulgando propostas de reordenação do país nos moldes cristãos, ou seja, construir a "alma brasileira". Já, a Liga Eleitoral Católica agiu como forte agente da fragmentação política e partidária do país no período que antecede o golpe de 1964 e sempre em defesa do ensino religioso, contra o ensino laico, e do casamento religioso com validade civil.

A criação da Ação Católica, em 1935, fazia parte de recomendações do Vaticano, atendendo à solicitação do papa Pio XI, em 1922, para que fossem fundadas em todo o mundo associações leigas, vinculadas à Igreja, destinadas ao apostolado, e foi a que menos objetivo político possuía até sua desagregação final em agrupamentos políticos, a maioria de caráter esquerdista. Assim, além da Juventude Operária Católica (JOC), outros grupos de atuação nacional, como a Juventude Agrária Católica (JAC) e Juventude Universitária Católica (JUC), foram reconhecidos oficialmente e implantados. Pode-se aceitar que o modelo de organização e a concepção de apostolado que cabia aos leigos do ponto de vista da Ação Católica aproximavam-se das ideias do Pe. Lebret, quando se propunha a se inserir na vida prática das pessoas por meio das técnicas de conhecimento que desenvolvera. À Ação Católica se opôs um grupo que se dedicou preferencialmente à "Tradição Família e Propriedade", entidade católica ultraconservadora.

Associado a esse quadro, em virtude do papel da hierarquia nos acontecimentos futuros, o Pe. Lebret enfrentou outro tipo de conflito relacionado ao ambiente de profunda desconfiança em que se desenrolavam as atividades políticas no país. Esse período em que a presença de Lebret constituiu objeto de investigação foi marcado pela Guerra Fria. O país estava dividido entre dois grandes grupos, os que se alinhavam com a política externa dos Estados Unidos e os que não se alinhavam a ela, entre esses últimos, aqueles que estavam vinculados à política externa da União Soviética, entretanto, a maioria estava simplesmente preocupada com uma política que traduzisse o interesse nacional. 
Além disso, assinalei ainda que permeava no cenário político a ideia do candidato único ou do candidato da união nacional que perpassava toda a vida pública brasileira de 1946 a 1964, constituindose num fator-chave para fragilizar a vida partidária, principalmente depois do Acordo Interpartidário que deu a Dutra a oportunidade de governar sem oposição, uma vez que patrocinou junto às lideranças do Congresso, uma coalizão política, formada pelo PSD, a UDN e o PR, com o objetivo de isolar o PTB no cenário político nacional. Entretanto, o Acordo Interpartidário não resolveu o principal problema para o qual fora criado, o da sucessão presidencial que girava em torno de buscar o candidato único, ou candidato de união nacional, no molde da Velha República. A partir dessa análise constatei que a sucessão presidencial no Brasil foi sempre um fator de instabilidade política, dando ensejo ao aparecimento de um fenômeno muito brasileiro, que é o golpismo.

Denominei golpismo a uma prática política relacionada à contestação permanente da legitimidade das eleições presidenciais pelos derrotados. Faz parte do golpismo e o caracteriza a presença de partidos políticos organizados e de expressão nacional, com a atuação paralela de entidades suprapartidárias, organizando, de forma sistemática, blocos parlamentares ou movimentos eleitorais fora ou à margem do sistema partidário existente, além da presença permanente e organizada dos militares nas atividades estritamente políticas.

Dessa forma, demonstrei que o que caracteriza o Brasil quando da presença de Lebret é o golpismo. Ora, se Lebret havia de atuar no Brasil, ele havia de atuar num contexto, de forte conteúdo golpista, bem como num ambiente político em que as entidades organizadas pela Igreja Católica exerciam um papel fundamental na desorganização da vida partidária, particularmente por meio da Liga Eleitoral Católica. Sendo que o coroamento da ação da Igreja nessa atividade desagregadora fora a sua participação na derrubada do Governo Constitucional de João Goulart, com a ação efetiva da Campanha da Mulher Democrática (Camde), organizada pelas senhoras católicas sob inspiração de padres, particularmente com o padre Peyton, e o patrocínio explícito da alta hierarquia católica.

A partir do desenvolvimento desses fatores mostrei que, nesse contexto tão conturbado, foi muito difícil dar a mesma relevância à presença de Lebret no país, como querem os intelectuais e técnicos planejadores, para dar ao suposto modelo paranaense um corte democrata cristão que o faria diferente dos demais, uma experiência única e exclusiva do Paraná. Essa ideia da exclusividade paranaense foi a chave para a compreensão do tipo de ideologia que estava associada 
ao transplante de uma experiência europeia para as condições do Brasil, principalmente no contexto político do golpismo.

No capítulo 4 tratei dos "Três Paranás" e a ideologia da integração, onde discuti a divisão econômica, política e cultural do Paraná em virtude de um fenômeno regional que foi a imensa faixa de expansão da fronteira agrícola baseada em sua maior extensão em empreendimentos imobiliários.

A expressão "os três Paranás" traduz a preocupação da oligarquia familiar à qual pertencia Ney Braga, e que foi formulada pela intelectualidade paranaense, constituindo a base para a construção de uma variante da ideologia integracionista, fortemente mobilizadora, que é o "Paranismo".

Essa ideologia dava o tom à política paranaense até a ascensão de Paulo Pimentel, quando o problema da hegemonia de um grupo político tradicional foi posto em xeque pelas forças econômica, social e política formadas pela grande migração que ocupou o Norte do Paraná. Tratava-se, portanto, de uma ideologia muito particular destinada a legitimar a hegemonia política de uma oligarquia familiar diante de um Estado fracionado em unidades culturais, políticas e econômicas distintas.

Os dois primeiros itens do capítulo constituem o pano de fundo histórico, ou seja, tratam respectivamente da política de povoamento dirigida pelo Estado, desde a emancipação da 5. ${ }^{a}$ Comarca de Curitiba e, depois, da formação no território paranaense de três unidades geográficas diferentes, tanto do ponto de vista político e econômico quanto cultural. No item seguinte, apresentei a exploração desse assunto e dessa realidade no imaginário político. Os aspectos analíticos foram retirados das Mensagens enviadas pelos governadores Bento Munhoz da Rocha, Moysés Lupion e Ney Braga anualmente ao Poder Legislativo, além de discursos e plataformas de governo. Nos últimos itens do capítulo, demonstrei como todo o sistema de planejamento e o governo Ney Braga representavam e expressavam uma forma particular de ideologia voltada para a necessidade da integração política, cultural e econômica sob a égide da oligarquia hegemônica, cuja base era o Paraná Tradicional em contraposição ao Norte e ao Sudoeste. Essa divisão fora a base de contestação da hegemonia política da oligarquia Munhoz da Rocha e Camargo. Para a análise desse capítulo, além das Mensagens e plataformas de governo, constituíram também referência as obras de Ruy Wachowsky e Wilson Martins.

A construção de uma ideologia da integração para assegurar a hegemonia de um grupo político passava pela eleição de um inimigo externo que ameaçava o Paraná de todos os paranaenses. Isso 
foi possível com base na ideia de ser o Paraná uma economia periférica num quadro dominado pelos centros dinâmicos, particularmente São Paulo. A ideia de uma economia periférica em que o centro dinâmico da economia nacional atuava como um fator de extração de renda estava na base do Plano Paranaense de Desenvolvimento e da criação da Codepar, e estava presente nos Estudos Econômicos da Pladep, de 1955. Dessa forma, não era difícil acrescentar um modelo de substituição de importações, dessa vez em relação aos produtos importados de São Paulo.

Essa visão pode ser encontrada nos textos que serviram de base para o "modelo paranaense de desenvolvimento" e na tese de Pedro Calil Padis, que deu expressão acadêmica ao problema em foco. Entretanto, tanto um como outro utilizaram de forma muito ligeira a tese cepalina das relações centro-periferia, vendo a economia paranaense como sendo periférica e dependente do polo paulista. Nesse sentido, procurei demonstrar que essa relação de dependência entre a economia paranaense e a economia paulista, ainda que não pudesse ser explicada nos termos que orientavam o "modelo paranaense de desenvolvimento" e nem a tese de Padis, fazia parte das estruturas mentais da população que buscava manter uma identidade cultural.

Ademais, mostrei também a contestação da adoção do modelo centro-periferia quando foi alegado que ele seria aplicável somente às condições da divisão internacional do trabalho. Todavia, apontei para vários aspectos da economia paranaense que podiam ser explicados pela ideia de que o atraso poderia ser tributado ao fato de São Paulo - com uma indústria protegida por tarifas aduaneiras elevadas - e o confisco cambial, ambos retirando renda da economia regional, impedirem o financiamento de um parque industrial, uma vez que a indústria estimulada pela ação do Estado era o meio eficaz de superar o subdesenvolvimento.

A par disso, registrei que independentemente da precisão conceitual do modelo analítico de centro-periferia, ele possuía forte aderência às condições concretas de uma comunidade que disputava um lugar no contexto nacional, particularmente diante de um quadro histórico de profundas disparidades regionais que foram acentuadas pela industrialização acelerada do período Kubitschek.

Nesse contexto, era fundamental criar uma ideologia que levasse à necessidade de integração do Estado do Paraná diante do processo de ocupação que resultou na divisão em três unidades geográficas, econômicas e culturais distintas. Para isso, a existência de um inimigo comum caía como uma luva para o grupo político a que pertencia Ney Braga, que sabia que sua hegemonia estava na iminência de ser contestada. Uma ideologia para isso era fundamental e ela veio à tona quando técnicos governamentais e burocratas que circulavam entre a academia e os cargos da 
administração pública começaram a racionalizar o que teria sido a experiência paranaense de planejamento. Com isso, constatei que a continuidade deles no aparelho de Estado, bem como a continuidade dos referenciais teóricos que informavam suas análises da economia e da sociedade paranaenses, tornou-os agentes relevantes dessa reconstrução histórica, baseada no papel central que o Estado deveria desempenhar no desenvolvimentismo, ou seja, no papel estratégico que eles mesmos haviam desempenhado.

O primeiro passo para essa exposição foi construir a ideia de que essa experiência era inédita no Brasil e que, mais uma vez, fazia do Paraná "o Brasil diferente" e apontei para a primeira iniciativa que foi a de atribuir essa diferença à doutrina democrática cristã que informava as ações do governo Ney Braga. Dessa forma, procurei demonstrar que o que estava acontecendo era o ressurgimento do paranismo; este sim uma ideologia com extrema vitalidade e apropriada para definir o papel central que cabia a uma elite tradicional desempenhar.

Assim, com a junção de dois elementos essenciais, um plano de desenvolvimento econômico e uma ideologia tradicional, o modelo paranaense de desenvolvimento econômico veio a ser a atualização, sob a forma economicista, do paranismo. Então, em minha tese, a ideologia que informa as análises do plano de desenvolvimento ou da existência de um modelo paranaense de desenvolvimento econômico é o paranismo.

O pano de fundo para o desenvolvimento dessa análise foi a ocupação do Norte e do Sudoeste (Extremo-Oeste e Sudoeste) paranaense onde se organizou um vasto sistema produtivo que se diferenciava do restante do Paraná. Foi esse quadro que criou a base material para a emergência de qualquer grupo que quisesse contestar a hegemonia política que a família Munhoz e Camargo vinha tentando reconstruir. E Ney Braga, membro dessa oligarquia familiar, se deu conta da necessidade de um compromisso político que incorporasse esses novos grupos, de modo a assegurar a permanência da oligarquia familiar.

A ocupação dessa imensa fronteira trazia para o Paraná enormes contingentes populacionais de outros estados, de tal forma que as divisões e diferenças internas reforçaram no Paraná a característica de ser gente de fora, ou seja, que não eram apenas diferenças regionais, pois cada região assumia características próprias que as vinculavam aos seus locais de origem e não ao Estado do Paraná. Assim, mostrei que desde a emancipação da $5 .{ }^{a}$ Comarca de Curitiba, o Paraná precisou criar uma identidade para uma coletividade sem nome, pois deixavam de ser curitibanos para ser outra coisa que ainda não havia existido. 
No Norte do Paraná instalou-se uma comunidade que culturalmente não se identificava com o Paraná Tradicional, mas que se assentava no projeto econômico do café ligado estreitamente à economia paulista e às casas exportadoras de São Paulo e Santos. Esse fenômeno era acompanhado pelo deslocamento do peso eleitoral do Paraná Tradicional para essas novas regiões, particularmente o Norte do Esatdo, que, já em 1960, representava metade do colégio eleitoral do Paraná. Além disso, como já foi dito, o café trouxe o capital comercial representado pelas casas exportadoras de São Paulo e Santos, impedindo em grande medida que os excedentes do café fossem transferidos para outros setores da economia do Estado, no sentido de estimular na economia local um salto para a industrialização.

A segunda frente de expansão foi a gaúcha, que ocupou o Sudoeste do Paraná por meio de projetos de colonização dirigidos por imobiliárias do Rio Grande do Sul para direcionar para fora do seu território as pressões que surgiram sobre as terras dos pampas, pertencentes aos grandes estancieiros que dominavam a vida econômica e política daquele estado. Esses migrantes trouxeram para o Paraná uma nova variante da criação de porcos em regime safrista, aumentando a área do estado voltada para essa atividade. Contudo, também a ocupação do Sudoeste não foi um fator que levasse a um processo de industrialização.

Em decorrência desses eventos todos, evidenciei como surgiu no imaginário da população, e particularmente na visão dos homens que exerciam a hegemonia política no Paraná, a divisão do estado em "Três Paranás" em que o Norte e Sudoeste se opunham em termos culturais e políticos ao Paraná Tradicional. Essa realidade foi traduzida de forma diferente pelos políticos que dirigiram o Paraná nesse período, em que o estado deixou de ser um deserto de gente para se tornar o maior produtor mundial de café.

Bento Munhoz foi o primeiro governador consciente da necessidade de uma estratégia integracionista no plano cultural, associando ao processo de ocupação do território paranaense uma ideologia integracionista fortemente paranista e vinculada estreitamente ao papel de Curitiba como a capital de todos os paranaenses e que transparece nas comemorações do centenário da emancipação política, quando organizou a "Comissão Geral de Obras para os Festejos do Centenário".

Entretanto, foi Ney Braga quem percebeu que o domínio da oligarquia familiar a que pertencia pelo casamento estava chegando ao fim, quando identificou as três tendências distintas que atuavam na economia paranaense, sendo que a do Norte cafeeiro e a economia agrícola de 
mercado do Sudoeste penetravam e se sobrepunham à estrutura agrária do Paraná Tradicional, constituindo estruturas em choque uma com as outras. Dessa compreensão que teve passou a dedicar-se ao esforço derradeiro para que tudo ficasse como antes.

A partir daí, Ney Braga elegeu um inimigo a combater, o centro hegemônico da economia brasileira, São Paulo, e identificou-o como responsável pelas dificuldades pelas quais passava o Paraná, que não conseguia dar um salto rumo à industrialização e libertar-se das contingências e inseguranças típicas de uma economia sujeita a flutuações de preços e quebras de safras. Dessa forma, surgiu o projeto ou modelo paranaense de desenvolvimento e que se prestou a atualizar o paranismo. Assim, provei que o chamado modelo paranaense de desenvolvimento foi a experiência de uma coletividade em busca de um novo destino e que permitiu a construção de um discurso ideológico de legitimação oligárquica. A base desse discurso, e que lhe deu legitimidade, era o paranismo. O fator de identificação da coletividade do Paraná Tradicional teve início com Romário Martins e sobreviveu passando por recorrentes processos de atualização. Do mesmo modo, demonstrei que o projeto ou modelo paranaense de desenvolvimento, conforme sua racionalização pelos técnicos e intelectuais envolvidos com ele, foi uma forma de ideologia de integração, que definiu a pertinência de pessoas a um grupo identificado como paranaense e que se encontrava ameaçado.

Para concluir, por todo o exposto, demonstrei que a Democracia Cristã foi o transplante inadequado de uma doutrina tipicamente europeia para as condições diferentes do Brasil e que se prestava a justificar a hegemonia de um grupo político. Para isso, declarei que a doutrina política inspirada na Democracia Cristã não informava as ações do governo Ney Braga, que se inscreviam nas mesmas práticas desenvolvimentistas predominantes, particularmente na implantação de uma infraestrutura que, de fato, é mais uma ação de Estado do que de governos.

Igualmente, comprovei que o discurso elaborado posteriormente sobre a existência de uma experiência de planejamento e de governo tipicamente paranaenses não passava da racionalização, por parte de intelectuais, técnicos e burocratas extremamente qualificados, dos eventos dos quais participaram ativamente. Dessa forma, mostrei que a invocação de Lebret tanto pelo governo quanto pelos intelectuais tinha um nítido caráter ideológico e, ao mesmo tempo, se prestava a certo nobilitamento dos intelectuais locais que tiveram a oportunidade de com ele trabalhar.

A partir daí, demonstrei que o fenômeno ideológico era a racionalização e a atualização do "paranismo", um sistema de crenças, valores e códigos de comportamento elaborado pela coletividade 
do Paraná Tradicional. Com isso, destaquei que, no centro dessa construção estavam os modelos de explicação da situação estadual fundados na relação centro-periferia, originaria da Cepal. Essa relação centro-periferia foi analisada no sentido de mostrar que, independentemente de sua validade teórica e conceitual, orientava a intelectualidade no processo de reconstrução da experiência política de uma forma totalmente nova, mas que se prestava a justificar também sua própria experiência nesses órgãos de planejamento.

\section{REFERÊNCIAS}

AQUINO, Tomás de. Suma teológica. In: CHATELET, François; DUHAMEL, Olivier; PISIER, Evelyne. Dicionário das obras políticas. Rio de Janeiro: Civilização Brasileira, 1993. p.12071218.

AUGUSTO, Maria Helena Oliva. Intervencionismo estatal e ideologia desenvolvimentista. São Paulo: Símbolo, 1978.

BENEVIDES, Maria Victoria. A UDN e o udenismo. São Paulo: Paz e Terra, 1981.

BIELSCHOWSKY, Ricardo. Pensamento econômico brasileiro: o ciclo ideológico do desenvolvimentismo. Rio de Janeiro: Contraponto, 1996.

CAMACHO, Ildefonso. Doutrina social da Igreja: uma abordagem histórica. São Paulo: Loyola, 1995.

CARDOSO, Miriam Limoeiro. Ideologia do desenvolvimento - Brasil: JK-JQ. 2.ed. Rio de Janeiro: Paz e Terra, 1978.

FORTES DE SÁ JR., Adherbal; NASCIMENTO, Gladimir. Ney Braga: tradição e mudança na vida política. Curitiba: Editora do Autor, 1996.

IANNI, Octavio. Estado e planejamento no Brasil (1930-1970). 2.ed. Rio de Janeiro: Civilização Brasileira, 1977. 
KUNHAVALIK, José Pedro. Ney Braga: trajetória política e bases do poder. In: OLIVEIRA, Ricardo Costa de (Org.); SALLES, Jefferson de Oliveira; KUNHAVALIK, José Pedro. A construção do Paraná moderno: políticos e política no governo do Paraná de 1930 a1980. Curitiba: SETI, 2004.

LAFER, Celso. O planejamento no Brasil: observações sobre o Plano de Metas (1956-1961). In: MINDLIN, Betty. Planejamento no Brasil. São Paulo: Perspectiva, 1997.

LEÃO, Igor Zanoni C. Carneiro. As desventuras do paranismo. Revista da FAE, v.2, n.3 set./ dez. 1999.

LEBRET, Louis-Joseph. Princípios para a ação. 8.ed. São Paulo: Duas Cidades, 1984.

LIMA, Alceu Amoroso. A Ordem, p.186-9, jul./ago./set. 1947.

MAGALHÃES FILHO, Francisco de Borja B de. Da construção ao desmanche: análise do projeto de desenvolvimento paranaense. Curitiba: IPARDES, 2006. (Coleção Clássicos da Economia e Sociedade Paranaense).

MANNHEIM, Karl. Liberdade, poder e planificação democrática. São Paulo: Mestre Jou, 1972.

MANNHEIM, Karl. A planificação como domínio racional do irracional. In: MARTINS, José de Souza; FORACCHI, Marialice Mencarini. Sociologia e sociedade. Rio de Janeiro: LTC, 1977.

MARITAIN, Jacques. Cristianismo e democracia. Rio de Janeiro: Agir, 1957.

MARITAIN, Jacques. O homem e o estado, 1953. In: CHATELET, François; DUHAMEL, Olivier; PISIER, Evelyne. Dicionário das obras políticas. Rio de Janeiro: Civilização Brasileira, 1993. p.774-778.

MARTINS, Wilson. História da inteligência brasileira - (1915-1933). 2.ed. São Paulo: T. A. Queiroz, 1996. v.6-7.

MARTINS, Wilson. Um Brasil diferente: ensaios sobre fenômenos de aculturação no Paraná. São Paulo: T. A. Queiróz, 1989.

MARTINS, Wilson. A invenção do Paraná. Curitiba: Imprensa Oficial, 1999.

MINDLIN, Betty. Planejamento no Brasil. São Paulo: Perspectiva, 1997. 
MONTORO, Franco. Ideologias em luta: respostas aos desafios do subdesenvolvimento. Rio de Janeiro: Ed. Companhia Brasileira de Artes Gráficas, 1966.

OLIVEIRA, Ricardo Costa de. Notas sobre a política paranaense no período de 1930 a 1945 . In: OLIVEIRA, Ricardo Costa de (Org.); SALLES, Jefferson de Oliveira; KUNHAVALIK, José Pedro. A construção do Paraná moderno: políticos e política no governo do Paraná de 1930 a1980. Curitiba: SETI, 2004.

PADIS, Pedro Calil. Formação de uma economia periférica: o caso do Paraná. 2.ed. Curitiba: IPARDES, 2006 (Coleção Clássicos da Economia e Sociedade Paranaense).

STOPPINO, Mario. Ideologia. In: BOBBIO, Norberto; MATTEUCCI, Nicola; PASQUINO, Gianfranco. Dicionário de política. 5.ed. São Paulo; Brasília: Imprensa Oficial-UNB, 2004.

WACHOWICZ, Ruy Christovam. História do Paraná. 6.ed. Curitiba: Vicentina, 1988.

THE UP-TO-DATE PARANISMO: CHRISTIAN DEMOCRACY AND PLANNING AT THE FIRST NEY BRAGA ADMINISTRATION 


\begin{abstract}
This article is a summary of the dissertation addresses the first Ney Braga administration (1961-1965), perceived as an innovative experience that, propped up by the Christian Democratic Party and based on Christian Democracy ideology, originated the Paraná Development Plan, developed by Sagmacs under the guidance of Father Lebret. The study attempts to show that the actions taken by this administration were much closer to a developmentalist ideology, thanks to the adoption of postulates typical of a center-periphery ECLACian approach, than to guidelines derived from Christian Democracy. It ascertains, then, the continuity of developmentalist models used by previous state and central administrations as a recurrent government practice. In this process, it points out that the intellectuals that made reference to this experience were actually rehashing a very particular vision of Paraná, known as "Paranismo", that is, a system of values grounded on the idea of a Paraná different from the rest of Brazil. Therefore, this study can assert that "Paranismo" is an ideology mode oriented toward the integration of a territory divided by its occupation process. Manheim's theoretical contributions were seminal to this study, especially in regard to ideology and the role played by a group of intellectuals - intelligentzia - in planning. Equally important was Miriam Limoeiro's study on developmentalism and the developmentalist ideology inbuilt in speeches by Juscelino Kubitschek and Jânio Quadros. Also very important were investigations by Maria Helena Oliva Augusto, on Codepar, and by Francisco Borja de Magalhães, on the planning model used in Paraná, which paved the way for analysis and interpretation of planning in the State of Paraná.
\end{abstract}

Keywords: Ney Braga administration. Christian Democracy. Christian Democratic Party. Sagmacs. Developmentalist ideology. 